\title{
Hemocultivo y mielocultivo en el curso de la fiebre tífica tratada con cloramfenicol
}

\author{
DRES.: LUIS FIDEL AVENDAÑO *, ISIDORO HORWITZ * y HAYDEE SEPULVEDA* *
}

INTRoDuCción. En la actualidad se ha acumulado abundante literatura sobre fiebre tifoidea, siendo bastante conocida su sintomatología, diagnóstico y tratamiento $(1,2,3,4,5,6,7,8)$. Se sabe, asimismo, que los problemas más importantes que aún subsisten lo constituyen las recaidas y la presencia de portadores $(9,10,11)$. También se ha estudiado extensamente la evolución tratada con cloramfenicol, tanto en sus aspectos clínicos como de laboratorio. Por otro lado, hay claras evidencias que durante algunas etapas de la patogenia de la enfermedad el germen se hace intracelular, lo que puede inplicar disminución de la efectividad de los mecanismos de defensa y posiblemente de las drogas antimicrobianas. Incluso este hecho podría ser un factor determinante de la presencia de portadores $(11,13)$.

Se ha estudiado el rendimiento del hemocultivo y del mielocultivo en la tifoidea como medio diagnóstico $(12,13)$, pero no se sabe cuánto tiempo permanecen los gérmenes en la sangre y en la médula ósea, órganos fundamentales del sistema de defensa del individuo; tampoco se sabe cómo influye sobre ellos el tratamiento antibiótico. En consecuencia, decidimos observar la evolución de estos dos índices, hemocultivo y mielocultivo, en pacientes de fiebres tíficas sometidos a tratamiento con cloramfenicol.

Material Y MÉtodo. Se estudian 29 niños con fiebres tíficas hospitalizados en la Unidad de Infecciosos del Hospital Roberto del Río. Se les practicó hemocultivo $\mathrm{y}$ mielocultivo al ingreso al servicio, con técnicas corrientes $(12,14)$, realizando el estudio bacteriológico por siembra inmediata de $1 \mathrm{cc}$. de sangre y $1 \mathrm{cc}$. de médula ósea. A estos enfermos, cuyos hemocultivos y/o mie-

\footnotetext{
* Departaminto de Pediatría. Hospital Robcrto del Rio.
}

locultivos fueron positivos al ingreso, se les hizo control cada tres días basta su negativización. Con el objeto de aumentar la sensibilidad del hemocultivo en los controles se sembró $1 \mathrm{cc}$. de sangre en cada uno de cuatro matraces. Los mielocultivos de control se hicieron con igual técnica que al ingreso.

Como tratamiento se indicó cloramfenicol en dosis de $50 \mathrm{mg}$. $/ \mathrm{kg} /$ día, vía oral, fraccionado cada 12 hrs., hasta completar 2 días afebriles, reduciendo entonces la dosis a la mitad, cubriendo un período mínimo de 8 días afebriles y 15 días de tratamiento antibiótico. Este último se prolongó en algunos casos hasta la negativización de los cultivos.

La edad de los pacientes fluctuó entre 2 y 14 años, distribuyéndose en 22 mujeres y 7 hombres.

Resultados. En los 29 casos la duración de la fiebre fue en promedio de 4,3 días, con variación entre 1 y 9 días. En forma paralela, el hemocultivo se negativizó en promedio de 5,5 días, con rango de 3 a 13 días. El mielocultivo tardó 6,4 días en hacerse negativo como promedio, con fluctuación entre 2 y 26 días. Gráficos $N o ̛$ No 2. No se observó complicaciones derivadas de la punción medular.

Discusión Y COMENTARIOS. En el presente estudio se observa que la evolución clínica de los pacientes no difiere, en cuanto a caída de la ternperatura y mejoría del estado general, de las experiencias comunicadas anteriormente sobre fiebres tíficas tratadas con cloramfenicol $(1,2,3$, $4,6)$. Sin embargo, parece no haber coincidencia entre la mejoría clínica y la presencia de gérmenes en el sistema retículo endotelial e incluso en la sangre, en un número no despreciable de enfer- 
GRAFICO No9

Relacion entre Estado Febril y Positividad de hemocultivos y mielocultivo en 29 casos de

Fiebrestificas tratados con Clorantenicol.

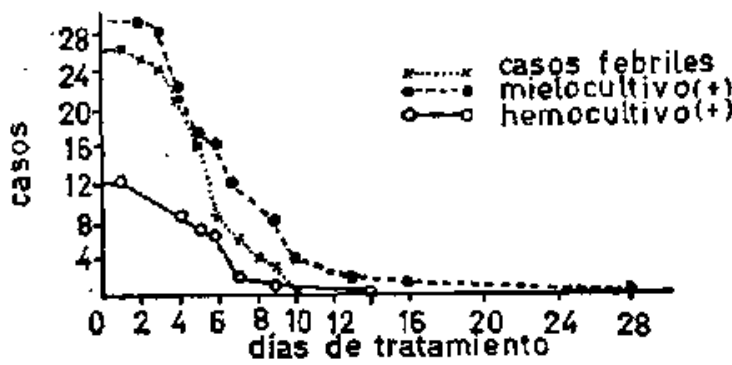

GRAFICO $\mathrm{NO}_{2}$

Positividad de hemocultivo y mielocultivo en 29 casos de Fiebres Tíficas tratados con Cloramfenicol.

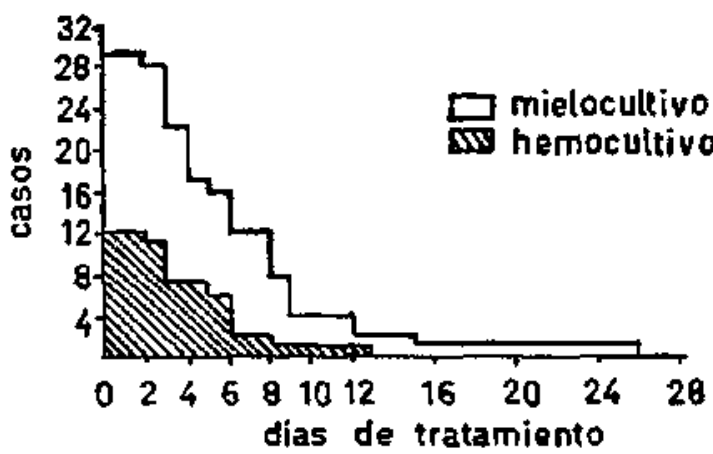

mos. En efecto, aunque la fiebre mejoró en un promedio de 4,3 días, la desaparición del germen de la sangre tardó 5,5 días y 6,4 días de la médula ósea. Aún más, hubo un grupo de 4 enfermos en los que el mielocultivo persistió positivo después de 10 días de tratamiento, e incluso en un caso después de 26 días, sin que ello implicara una evolución complicada o especialmente tóxica,

Resumen Y CONCLUSIONES. Se estudian 29 enfermos con fiebres tíficas comprobadas mediante hemocultivos y mielocultivos seriados, cada tres días, hasta su negativización, sometidos a tratamiento con cloramfenicol. Se observó caída de Ia fiebre en promedio de 4,3 días, negativización de los cultivos en promedios de 5,5 días para el hemocultivo y 6,4 días para el mielocultivo. En 4 enfermos el mielocultivo persistió positivo después de 10 días de tratamiento, habiendo mejorado el estado general y la fiebre varios días antes.

\section{REFERENCIAS}

1.- Meneghello, J.; Undurraga, O, y Raimann, A. "Cloramfenicol (Cloromicetina) en el tratamiento de la fiebre tifoidea del niño". Rev. Chil. Pediat., 21: 535,1950 .

2.- Meneghello, J.; Undurraga, O. y Rubio, S. "Fiebre tifoidea en el niño tratada con Cloromicetina suministrada cada 12 horas". Rev. Chil. Pediat., 22: $25,1951$.

3.- Kraljevic, R.; Perroni, J.; Pearson, E.; Sesnic, R.; González, O.; Borel, $H$.; Rojas, $M$. y Jiménez, $L$. "Cloromicetina y tifoidea. Experiencia sobre 500 casos". Rev. Méd. Chil., 80: 521, 1952.

4.-Wiederhold, A.; Infante, R.; Martorell, R.; Nazer, J. y Velásquez, $G$. "La fiebre tifoidea antes y después del uso de cloromicetina". Arch. Hosp. Roberto del Río, 20: 109, 1953.

5.- Menewhello, J.; Undurraga, O.; Izzo, C. y Raimann, A. "Perforación intestinal en la fiebre tifoidea del niño". Rev. Chil. Pediat., 26: 241, 1955.

6.-Lobos, H.; Olcese, A.; Undurraga, O. y Meneghello, J. "Fiebre tifoidea en el niño". Pediatría, 8; 11, 1965.

7.-Heredia, A. "Estudio clínico y de laboratorio de 437 niños con fiebre tifoidea". Bol. Méd. del Hosp. Infantil de México, 17: 723, 1960.

8.- Lattapiat, F.; Fanta, E.: Pino, M. y González, M. "Tratamiento de las fiebres tíficas en el niõo con ampicilina". Rev. Chil. Pediat., 38: 408, 1967.

9.-Meneghello, J.; Undurraga, O. y Raimann, A. "Recaídas en la fiebre tifoidea tratada con cloramfenicol". Rev. Chil. Pediat., 25: 119, 1954.

10.-Viel, B. y Aste, G. "Coprocultivo en enfermos de tifoidea tratados con cloramfenicol". Rev. Méd. Chil., 80: 399, 1952.

11.-Armijo, R,; Pizzi, A, y Lobos, H. "Prevalencia de portadores tíficos después del tratamiento con cloramfenicol". Bol. Ofic. Sanit. Panamer, 62: 295, 1967.

12.-Schlack, L., y Pino, $M$. "El mielocultivo en el diagnóstico de la fiebre tifoidea", Rev. Chil. Pediat., 37: 213, 1966.

13.- Randrianbologna, R. et Dodin, A. "Etude de l'EvoJution de la Bacterieme dans once cas de Salmonellose traittes. Ann. Inst. Pasteur, 99: 278, 1960.

14.- Pochedly, C. "How to perform bone marrow puncture in small children". Clinical Pediatrics, 8 : 705, 1969. 